
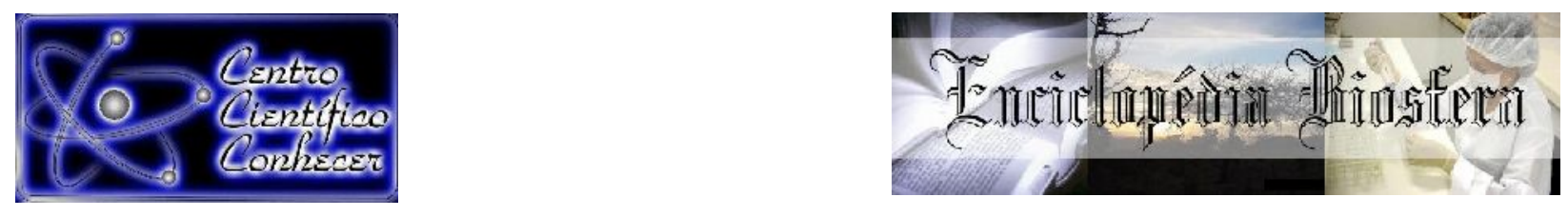

\title{
ANÁLISE DAS PUBLICAÇÕES BRASILEIRAS SOBRE EDUCAÇÃO AMBIENTAL COM ENFOQỦE NA TEMÁTICA MUDANÇAS CLIMÁTICAS
}

Cleirianne Rodrigues de Abreu'; Sabrina do Couto de Miranda²; Plauto Simão DeCarvalho ${ }^{3}$

${ }^{1}$ Mestre em Ensino de Ciências. Universidade Estadual de Goiás. E-mail: cleiriannne@gmail.com/sabrinac.miranda@gmail.com

${ }^{2}$ Professora de Botânica, docente Permanente no Mestrado Profissional em Ensino de Ciências. Universidade Estadual de Goiás.

${ }^{3}$ Professor de Botânica, docente Permanente no Mestrado Profissional em Ensino de Ciências. Universidade Estadual de Goiás.

Recebido em: 06/04/2019 - Aprovado em: 10/06/2019 - Publicado em: 30/06/2019 DOI: 10.18677/EnciBio_2019A135

RESUMO
Este trabalho teve por objetivos realizar uma análise dos artigos sobre Educação Ambiental publicados em periódicos nacionais e verificar como a temática Mudanças Climáticas tem sido abordada. Para tanto, foi realizada uma revisão sistematizada da literatura. Nas revistas selecionadas foram efetuadas buscas utilizando o termo "Educação Ambiental" e a combinação deste com "Mudanças Climáticas", "Gases de Efeito Estufa", "Aquecimento Global" e "Desmatamento" com o recorte temporal de 2005 a 2018. Os artigos selecionados tiveram os resumos analisados quanto ao tema trabalhado, perspectivas teóricas, objetivos, tipo de pesquisa e instrumentos utilizados para a coleta de dados. Além disso, foram identificados e analisados os trabalhos relacionados ao tema mudanças climáticas. Os dados mostraram que os artigos abordaram principalmente as relações entre homem, natureza, sociedade e sustentabilidade conjunto aqui classificado como Educação Ambiental lato sensu. As perspectivas teóricas estão voltadas sobretudo para a sustentabilidade, percepção dos problemas ambientais em diferentes escalas e para as políticas públicas. A maioria dos artigos tem por objetivos o desenvolvimento de ações e o diagnóstico de determinada problemática. Assim, em sua maioria as pesquisas são do tipo participante ou ainda pesquisa descritiva/exploratória. Quanto aos instrumentos de coleta de dados estes foram majoritariamente voltados à análise de conteúdo, eventos de formação, aplicação de questionários e realização de entrevistas. A análise mostrou que a temática mudanças climáticas é pouco trabalhada no contexto da Educação Ambiental, sendo uma importante lacuna a ser observada pelos estudiosos da área.

PALAVRAS-CHAVE: Ambiente, Clima, Educação, Sociedade 


\title{
ANALYSIS OF BRAZILIAN PUBLICATIONS ON ENVIRONMENTAL EDUCATION WITH A FOCUS ON THE THEME OF CLIMATE CHANGE
}

\begin{abstract}
The objectives of this work were to carry out an analysis of the articles on Environmental Education published in national journals and to verify how the Climate Change theme has been addressed. To this end, a systematic review of the literature was carried out. The selected journals were searched using the term "Environmental Education" and its combination with "Climate Change", "Greenhouse Gases", "Global Warming" and "Deforestation" with the temporal cut from 2005 to 2018. The selected articles had their abstracts analyzed regarding the theme worked, theoretical perspectives, objectives, type of research and instruments used for data collection. In addition, the work related to the topic of climate change was identified and analyzed. The data showed that the articles mainly addressed the relationships between man, nature, society and joint sustainability here classified as Environmental Education lato sensu. The theoretical perspectives are mainly focused on sustainability, perception of environmental problems at different scales and public policies. Most of the articles have as objectives the development of actions and the diagnosis of certain problems. Thus, most of the researches are of the participant type or even descriptive/exploratory research. As for the data collection instruments, these were mostly focused on content analysis, training events, application of questionnaires and conducting interviews. The analysis showed that the theme of climate change is little worked in the context of environmental education, being an important gap to be observed by scholars in the area.
\end{abstract}

KEYWORDS: Education, Environment, Climate, Society

\section{INTRODUÇÃO}

De acordo com a Lei no 9.795 de 27 de abril de 1999, a Educação Ambiental envolve processos que contribuem na construção de valores sociais, conhecimentos, habilidades e competências, no contexto individual ou coletivo, voltados para a conservação do meio ambiente. Nesta mesma lei, no segundo artigo tem-se que a Educação Ambiental deve ser um componente essencial para a educação nacional e estar presente no ensino com caráter formal e não formal (BRASIL, 1999). Com a inclusão da Educação Ambiental em todos os níveis e modalidades do ensino, o documento do Programa Nacional de Educação Ambiental propõe que o fomento do exercício da Educação Ambiental seja transversal com diálogos interdisciplinares e implementação de políticas públicas que fortaleçam a perspectiva transversal de modo contínuo e permanente (BRASIL, 2005).

A Educação Ambiental abarca uma multiplicidade de concepções que apresentam perspectivas, práticas e metodologias próprias, de modo que as suas essências são diferenciadas. Layrargues e Lima (2014) descreveram três macrotendências da Educação Ambiental no Brasil, sendo elas: Conservadora, Pragmática e Crítica. Em linhas gerais pode-se dizer que a Educação Ambiental Conservadora está vinculada a "Pauta Verde", com a promoção de práticas como trilhas interpretativas, dinâmicas agroecológicas e de percepções que ocorrem comumente em unidades de conservação e/ou em atividades de ecoturismo (LAYRARGUES, 2012). Para Sauvé (2005), a corrente denominada conservacionista e naturalista tem como características centrais: a educação entendida na sua dimensão individual, baseada em vivências de práticas; apoia-se em pedagogias comportamentalistas ou alternativas de cunho místico; baixa 
problematização da realidade e pouca ênfase em processos históricos; foco na redução do consumo.

$\mathrm{Na}$ macrotendência da Educação Ambiental Pragmática questões do lixo, coleta seletiva e reciclagem de resíduos centram-se no foco das atividades. Esta abrange as correntes da Educação para o Desenvolvimento Sustentável e Consumo Sustentável (LAYRARGUES; LIMA, 2014). Layrargues (2012) afirma que a vertente pragmática está fortemente presente nos meios midiáticos, principalmente na divulgação por empresas ao consumidor sobre o cuidado e a responsabilidade da mesma com o meio ambiente.

Por fim, na macrotendência da Educação Ambiental Crítica, também conhecida como transformadora, popular, emancipatória e dialogada, ênfase é dada na análise crítica dos fundamentos que proporcionam a dominação do ser humano e acumulação do Capital (LAYRARGUES; LIMA, 2014). Assim, segundo os referidos autores, há um forte viés sociológico e político, e no debate conceitos-chave como cidadania, democracia, participação, emancipação, conflito, justiça ambiental e transformação social são introduzidos. Segundo Layrargues (2012), a Educação Ambiental Crítica está crescendo nas discussões, mas ainda se encontra muito restrita ao âmbito das pós-graduações.

A exposição acima destaca inúmeras denominações associadas à Educação Ambiental, contudo para o público não especializado existe apenas uma vertente de Educação Ambiental, cujo objetivo é conscientizar as pessoas em relação à natureza e aos problemas ambientais com suas dimensões sociais e políticas (ABREU, 2017). Na modernidade, o padrão de desenvolvimento do ser humano está vinculado ao acúmulo de Capital e distanciamento da natureza. Esse acúmulo, por sua vez, faz com que o homem "aproprie-se" dos recursos naturais, provocando desequilíbrios no meio ambiente e problemas ambientais que comprometem a qualidade do ar e da água, causam desmatamento, alta produção de resíduos, intensificam o aquecimento global, ocasionam mudanças climáticas, entre outros. Esses problemas estão ligados a realidade local em variadas escalas: rua, bairro, município, estado, região e país, e envolvem aspectos econômicos, sociais e culturais (SILVA, 2008).

Nesta perspectiva as emissões de gases de efeito estufa (GEE) causadas pelas atividades humanas têm aumentado desde a era pré-industrial (VALVERDE; MARENGO, 2010). E evidências da influência humana sobre o aquecimento global têm crescido desde a década de 1990 quando dados científicos sistematizados começaram a ser divulgados nos Relatórios de Avaliação do IPCC (do inglês, Intergovernmental Panel on Climate Change) (VALVERDE; MARENGO, 2010). De acordo com o referido órgão as mudanças climáticas são variações estatisticamente significativas nas condições médias climáticas, ou em sua variabilidade. Estas persistem por longos períodos, podem ser resultantes de processos naturais, bem como, de mudanças antropogênicas persistentes na composição da atmosfera ou no uso do solo (IPCC, 2001, 2014).

Os GEE direto que se destacam com relação à quantidade de emissões e relação com as atividades humanas são: dióxido de carbono $\left(\mathrm{CO}_{2}\right)$ gerado na queima de combustíveis fósseis em processos industriais e transportes, bem como, mudanças de uso da terra; metano $\left(\mathrm{CH}_{4}\right)$ procedente das atividades agrícolas e uso de combustíveis fósseis; óxido nitroso $\left(\mathrm{N}_{2} \mathrm{O}\right)$ emitido a partir da fertilização na agricultura e atividades industriais (OLIVEIRA; ALVES, 2011).

O IPCC, no relatório publicado em 2014, afirmou que as mudanças nas temperaturas globais estão sendo ocasionadas por atividades humanas e os 
combustíveis fósseis continuam sendo os grandes responsáveis por estas alterações. Neste relatório os pesquisadores afirmam ainda que para manter o aumento médio da temperatura do planeta abaixo de $2^{\circ} \mathrm{C}$ até o ano de 2100 serão necessárias mudanças significativas na matriz energética dos países com reduções nas emissões de GËE nas próximas décadas (IPCC, 2014).

No caso do Brasil, o relatório do Painel Brasileiro de Mudanças Climáticas destaca aumentos de temperatura nas próximas décadas em diferentes regiões, entre $3^{\circ} \mathrm{C}$ e $6^{\circ} \mathrm{C}$, este ocasionará graves consequências sociais, ambientais e econômicas. Além disso, está prevista diminuição nas chuvas de até $40 \%$ no NorteNordeste, com impactos nos reservatórios das hidrelétricas (PBMC, 2014).

Outro aspecto importante é que as mudanças climáticas afetam de modo significativo o bioma Cerrado. Trata-se do segundo maior bioma brasileiro em extensão geográfica, abriga expressivo número de espécies de plantas superiores, bem como, as nascentes dos principais rios brasileiros (FERNANDES et al., 2016; FERREIRA et al., 2016). Apesar da importância do Cerrado em termos de serviços ecossistêmicos, sua vegetação vem sendo anualmente destruída, principalmente pelo desmatamento e conversão da vegetação nativa em terras agrícolas e pastagens (MIRANDA, 2012).

No contexto nacional em dezembro de 2009 foi instituída, pela Política Nacional de Mudanças Climáticas (PNMC), a lei 12.187 que apresenta como objetivo um desenvolvimento econômico e social que possa contribuir para a proteção do sistema climático. No artigo $5^{\circ}$ desta lei, uma das propostas das diretrizes é a "promoção da disseminação de informações, a educação, a capacitação e a conscientização pública sobre mudança do clima" (BRASIL, 2009). Assim, alguns mecanismos legais amparam a importância de se trabalhar por meio da Educação Ambiental o tema das mudanças climáticas.

As mudanças climáticas trazem desafios que vão além da redução das emissões de GEE, hoje há iminente necessidade de adaptação a um planeta mais quente. As medidas de adaptação devem ser abordadas de modo interdisciplinar com contextualização histórica, social e cultural do indivíduo, construindo uma visão mais crítica do conhecimento científico e tecnológico, e suas relações com a sociedade (MIRANDA et al. 2016).

A mudança global do clima é um dos mais significativos desafios da atualidade, uma vez que seus efeitos afetam a humanidade em diferentes contextos. Diante disso, a Educação Ambiental surge como um importante instrumento para se trabalhar a referida temática. Assim, este trabalho teve por objetivos realizar uma análise dos artigos sobre Educação Ambiental publicados em periódicos nacionais, bem como, dentre estes verificar como a temática mudanças climáticas tem sido abordada.

\section{MATERIAL E METODOS}

A coleta de dados foi realizada a partir de uma revisão sistematizada da literatura. Optou-se por analisar artigos publicados em revistas/periódicos classificados na Plataforma Sucupira da CAPES (Coordenação de Aperfeiçoamento de Pessoal de Nível Superior) Qualis Periódicos, no evento de classificação mais recente (classificação 2013-2016), com estratos B2, B1, A2 ou A1 nas Áreas de Avaliação "Educação" e "Ensino". As áreas selecionadas abarcam de modo mais intrínseco os trabalhos em Educação Ambiental e pressupõe-se que artigos publicados em periódicos com estratos de classificação superiores passam por 
maior rigor e crivo na seleção por pareceristas com maior qualidade de conteúdos, justificando a seleção realizada.

A partir da planilha gerada no Qualis Periódicos foram selecionados periódicos cujos nomes apresentavam os termos: "Educação", "Ambiental", "Ambiente", "Ciências" e "Sociedade". Posteriormente, foi feita uma nova triagem excluindo-se revistas específicas das áreas de matemática, teologia, ciências do esporte e educação física. Com esses critérios foram encontradas 80 revistas, nestas realizou-se buscas utilizando o termo "Educação Ambiental", bem como, a combinação deste com "Mudanças Climáticas", "Gases de Efeito Estufa", "Aquecimento Global" e "Desmatamento". É importante destacar que se estipulou o recorte temporal de 2005 a 2018 para as buscas de artigos. Delimitação do ano inicial deve-se a maior divulgação do conhecimento sistematizado sobre as mudanças climáticas nos veículos de comunicação graças às publicações do IPCC e do PBMC.

Os artigos encontrados, a partir dos termos escolhidos, foram baixados e tiveram os resumos analisados quanto ao tema trabalhado, perspectivas teóricas, objetivos, tipo de pesquisa e instrumentos utilizados para a coleta de dados (Adaptado de SANTOS; SILVA, 2011). Além disso, foram identificados e analisados de modo integral os trabalhos relacionados ao tema mudanças climáticas este apontado de maneira explícita no título, resumo e/ou palavras-chave. A análise foi feita de modo sistematizado com a técnica de Análise de Conteúdo. Nesta abordagem 0 interesse do pesquisador envolve compreender como se dá a produção do conhecimento em uma determinada área. Segundo Delizoicov e Lorenzetti (2008) e Santos e Silva (2011) estes estudos são relevantes pelo fato de procurarem analisar informações ocorridas em determinada área do saber, bem como, identificar as temáticas enfocadas em cada época, o público envolvido, os referenciais utilizados, entre outros. Pesquisas desta natureza também podem fornecer dados sobre o "comportamento" de uma determinada área do conhecimento ao longo de um período.

\section{RESULTADOS E DISCUSSÃO}

Com base nos critérios metodológicos delineados foram encontrados 625 artigos no total, a contextualização dos resultados se deu por meio da apresentação de dados representativos dos artigos selecionados. A análise mostrou que os temas mais recorrentes se relacionam à Educação Ambiental lato sensu (47,99\% do total) (Figura 1) que abarca a relação homem, natureza, sociedade e sustentabilidade, elementos presentes nas diferentes vertentes de Educação Ambiental. Temas relacionados às mudanças climáticas, tais como aquecimento global e desmatamento foram relativamente pouco mencionados nos artigos (Figura 1). Além disso, na categoria "outros" (Figura 1) foram inseridos assuntos que ocorreram com baixa frequência nos artigos, a saber: água e bacias hidrográficas, agrotóxicos, camada de ozônio, cultura e esporte, transportes, horta, solos, restauração, energia, tecnologias sociais, radiação e clima, ecossistema, ecologia, ciclo do nitrogênio, peixes, seres vivos, poluição e usinas hidrelétricas.

Nos artigos classificados dentro da temática Educação Ambiental lato sensu os autores buscaram analisar tendências teóricas e metodologias na produção acadêmica visando compreender a diversidade que constitui esse campo (PATO et al., 2009; RINK; MEGID NETO, 2009), bem como, as concepções dos educadores ambientais nas universidades (GOMES et al., 2009; CORREIA, 2014). Alguns desses trabalhos apontaram a emergência de temas que Pato et al. (2009) 
descreveram como "silenciados" pelos pesquisadores da área de Educação Ambiental. Os artigos também sugerem uma educação "socioambiental" como necessidade para um novo modo de relação da sociedade com o meio ambiente (PITANO; NOAL, 2009; PALÁCIOS et al., 2011; SAITO, 2011).

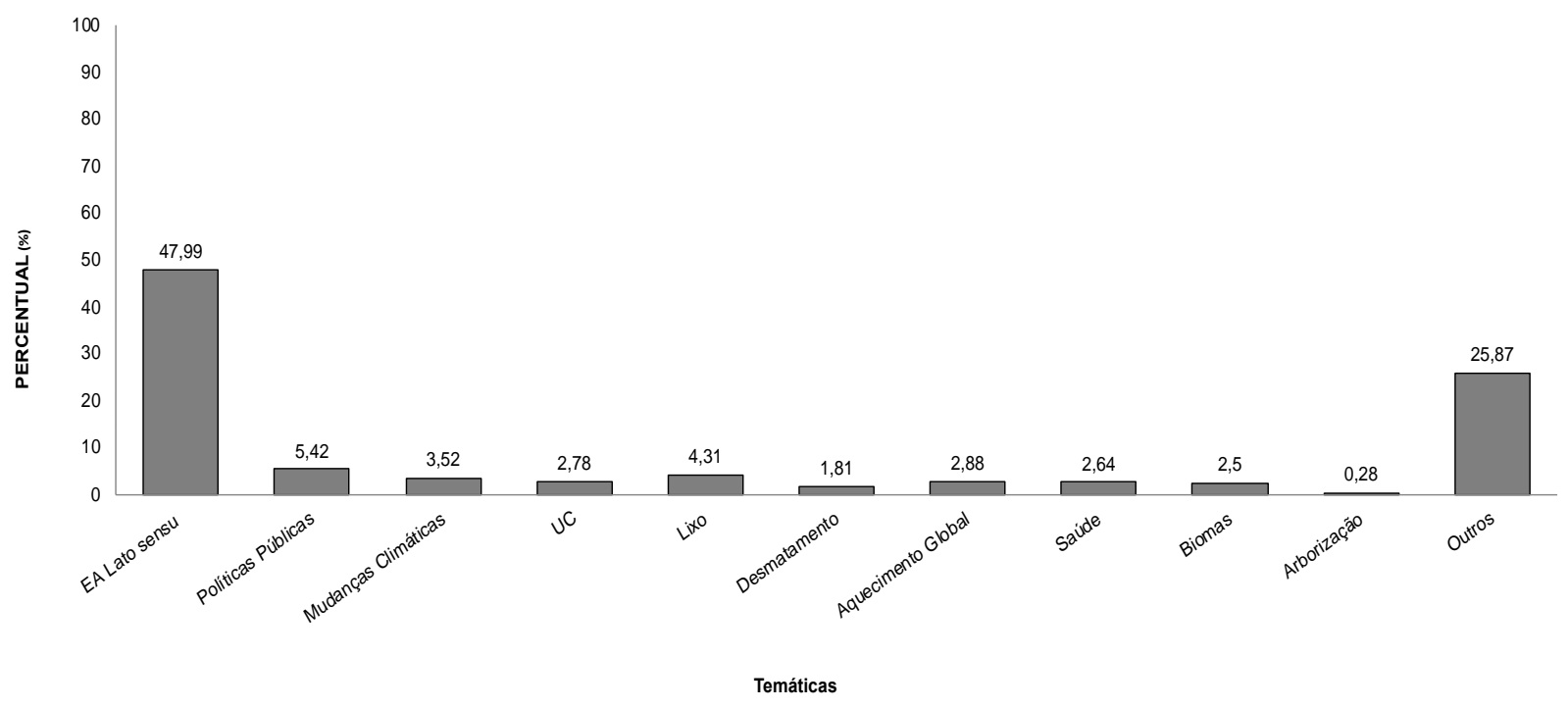

FIGURA 1: Temas abordados em artigos de Educação Ambiental publicados em periódicos nacionais da Área de Educação e Ensino no período de 2005-

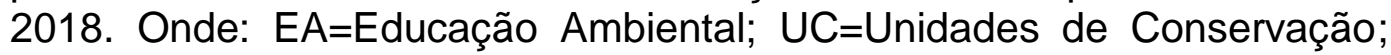
$\mathrm{GEE}=$ Gases de Efeito Estufa. Fonte: Autores.

No contexto das mudanças climáticas $(3,52 \%$ do total) (Figura 1$)$, foi encontrada análise testando a aplicabilidade da teoria da sociedade de risco de Ulrich Beck para a sociedade brasileira com distribuição da percepção de risco associada às mudanças climáticas e aquecimento global (BURSZTYN; ERIÓ, 2015). Também foram verificadas análises e reflexões sobre as questões das mudanças climáticas e a necessidade da formação da consciência crítica em busca de transformar a realidade (GUERRA et al., 2010). Proposta de elaboração de documento visando discussão e reflexão sobre a posição da política pública de Educação Ambiental com o tema mudanças climáticas (VASCONCELOS; TAMAIO, 2010). E ainda estudo onde os professores de ciências foram incentivados a ensinarem sobre mudanças climáticas de forma interdisciplinar com a preocupação de educar para a cidadania (BADER et al., 2014). Desse modo, a partir da metodologia proposta, tem-se que são poucos os trabalhos que abordaram as mudanças climáticas como tema nos trabalhos de Educação Ambiental.

Dentre as perspectivas teóricas identificadas nos artigos, destacam-se: Educação Ambiental para a sustentabilidade (21\%) e Educação Ambiental a partir da percepção (16,88\%) (Figura 2). A sustentabilidade está presente nos artigos com foco no desenvolvimento de projetos para condições sustentáveis (JIMENEZ; TERCEIRO, 2009), bem como, implementação de unidades de gestão ambiental para possibilitar o desenvolvimento sustentável (LIMA, 2013).

Macêdo e Souza (2014) buscaram em seu artigo analisar e discutir por meio da percepção dos professores da rede pública os problemas ambientais do Rio Grande do Norte. Com relação à Educação Ambiental com foco nas políticas 
públicas, Oliveira e Carvalho (2012) sistematizaram e discutiram os dados relativos aos documentos oficiais com foco na formação de professores para a Educação Ambiental. Malafaia e Rodrigues (2008) realizaram reflexões a respeito do ensino de ciências no ensino fundamental na perspectiva para a cidadania, com medidas que permitissem que os alunos fossem capazes de enfrentar situações cotidianas por meio dos modelos conceituais da ciência através de jogos e simulações.

As perspectivas CTS (Ciência, Tecnologia e Sociedade) e CTSA (Ciência, Tecnologia, Sociedade e Ambiente) foram relativamente pouco consideradas (Figura 2), apesar de suas relevâncias. Estas perspectivas dão espaço aos problemas sociais ligados ao desenvolvimento científico e tecnológico, logo, deveriam ter mais pesquisas investigativas que envolvessem a formação dos educadores ambientais com a temática mudanças climáticas. A inserção de discussões nestas perspectivas estimula o educando a sentir-se parte da sociedade, a se interessar pelos problemas e participar das tomadas de decisões (VIEIRA; BAZZO, 2007). Farias e Carvalho (2006) consideram que a perspectiva CTSA tem trazido contribuições para a Educação Ambiental ao questionar o estatuto da ciência e da tecnologia diante dos desafios relacionados ao desenvolvimento e a sustentabilidade.

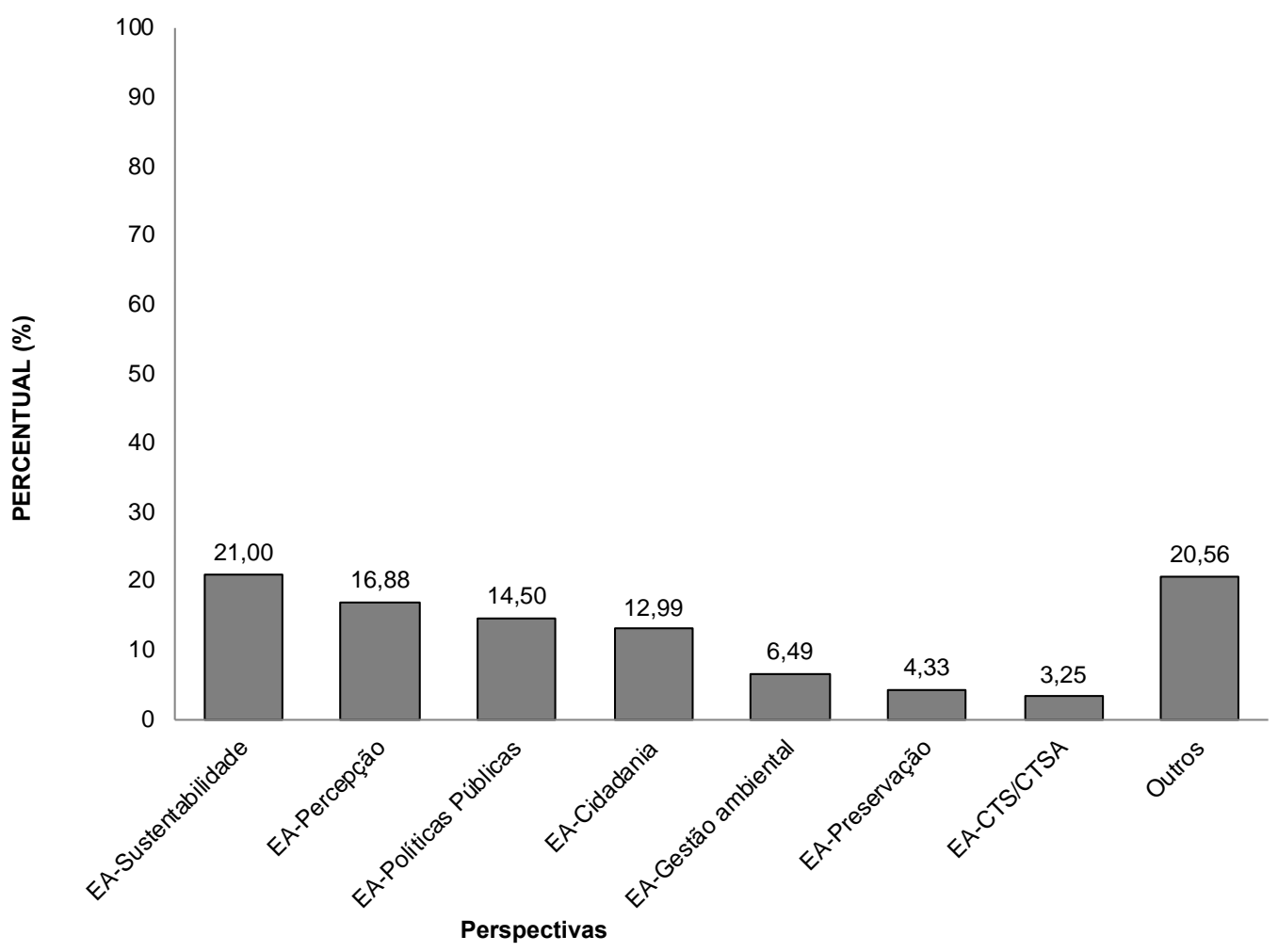

FIGURA 2: Perspectivas encontradas nos artigos de Educação Ambiental publicados em periódicos nacionais da Area de Educação e Ensino no período de 2005-2018. Onde: EA=Educação Ambiental; CTS=CiênciaTecnologia-Sociedade; $\quad$ CTSA $=\quad$ Ciência-Tecnologia-SociedadeAmbiente. Fonte: Autores.

Com relação aos objetivos, a maioria dos artigos abordou a Educação Ambiental com foco na ação (25,22\%) (Figura 3), para exemplificar tem-se alguns ensaios com experimentação e 0 uso de trilhas interpretativas (SAMPAIO; GUIMARAES, 2009); práticas realizadas em Unidades de Conservação como ação educativa (VALENTI et al., 2012; MAGALHÃES; TOMANIK, 2012); uso de 
plataformas como ferramentas para a aprendizagem colaborativa (MAIO et al., 2008); ação para identificar a percepção prévia de alunos sobre o ecossistema (RODRIGUES; FARRAPEIRA, 2008), entre outras.

Além desses, verificou-se ainda alta frequência de artigos que objetivaram realizar diagnósticos diversos por meio da análise de conteúdo (23,09\%) (Figura 3). Dantas e Abílio (2014) analisaram artigos publicados na Revista Eletrônica do Mestrado em Educação Ambiental e concluíram que existem diversas abordagens de Educação Ambiental na educação básica. Os autores sugerem ainda produção de artigos científicos que possam ser reproduzidos sem dificuldades. Farias et al. (2013) realizaram análise das ações de Educação Ambiental desenvolvidas no Centro de Educação Ambiental do Município de Lajeado com base nos documentos internacionais, federais e estaduais. Os autores verificaram que algumas ações cumprem os documentos, porém outras ações apenas parcialmente ou estão desvinculadas dos documentos. Latini e Sousa (2011) utilizaram a análise de conteúdo para identificar significados, concepções e articulação entre o ensino de Química e o ambiente. Os autores apontaram como sugestão a necessidade de maior problematização da questão ambiental nas publicações, visando o aumento da compreensão da ciência e do saber científico. A categoria "outros" (Figura 3) engloba análise de plataformas, atividades de campo e estudo do meio, análise de softwares, análise de kits ecológicos e análise do ar.

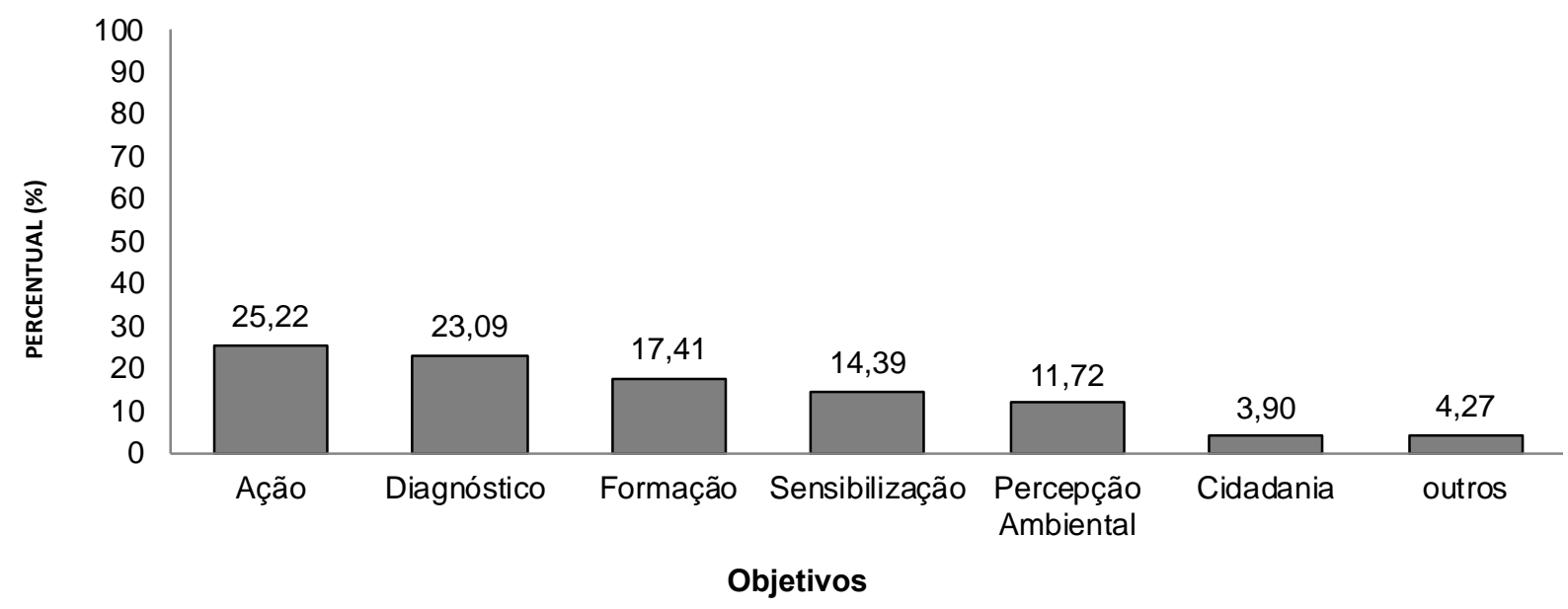

FIGURA 3: Distribuição dos objetivos encontrados em artigos de Educação Ambiental publicados em periódicos nacionais da Área de Educação e Ensino no período de 2005-2018. Fonte: Autores.

Dentre os tipos de pesquisas encontrados nos artigos, a pesquisa participante e a pesquisa-ação foram as mais utilizadas $(64,70 \%)$ (Figura 4). Em alguns trabalhos foram desenvolvidas dinâmicas com discussões onde os participantes podiam expor suas opiniões, ajudando, complementando ou discordando dos comentários dos colegas e/ou dos professores-investigadores. $\mathrm{Na}$ pesquisa-ação os participantes estão envolvidos em um problema coletivo no qual os pesquisadores também fazem parte de modo cooperativo ou participativo. Para exemplificar, Barros e Tozoni Reis (2009) realizaram um mapeamento ambiental com crianças, inspirados na metodologia da pesquisa-ação buscou-se soluções para ENCICLOPÉDIA BIOSFERA, Centro Científico Conhecer - Goiânia, v.16 n.29; p. 1751 2019 
os problemas vivenciados pelo grupo, o trabalho foi realizado com crianças da préescola de modo a reinventar o ambiente por meio da Educação Ambiental e das ações coletivas. Os autores Pato et al. (2009) afirmam que estudos participativos destacam a intervenção na realidade, de forma a mudar a relação que os sujeitos têm consigo mesmos e com o entorno. Isso pode indicar a vocação das pesquisas em Educação Ambiental para a transformação da realidade, em direção a relações mais sustentáveis para a pessoa, os grupos, a sociedade e o planeta, num processo de ação-reflexão-ação permanente.

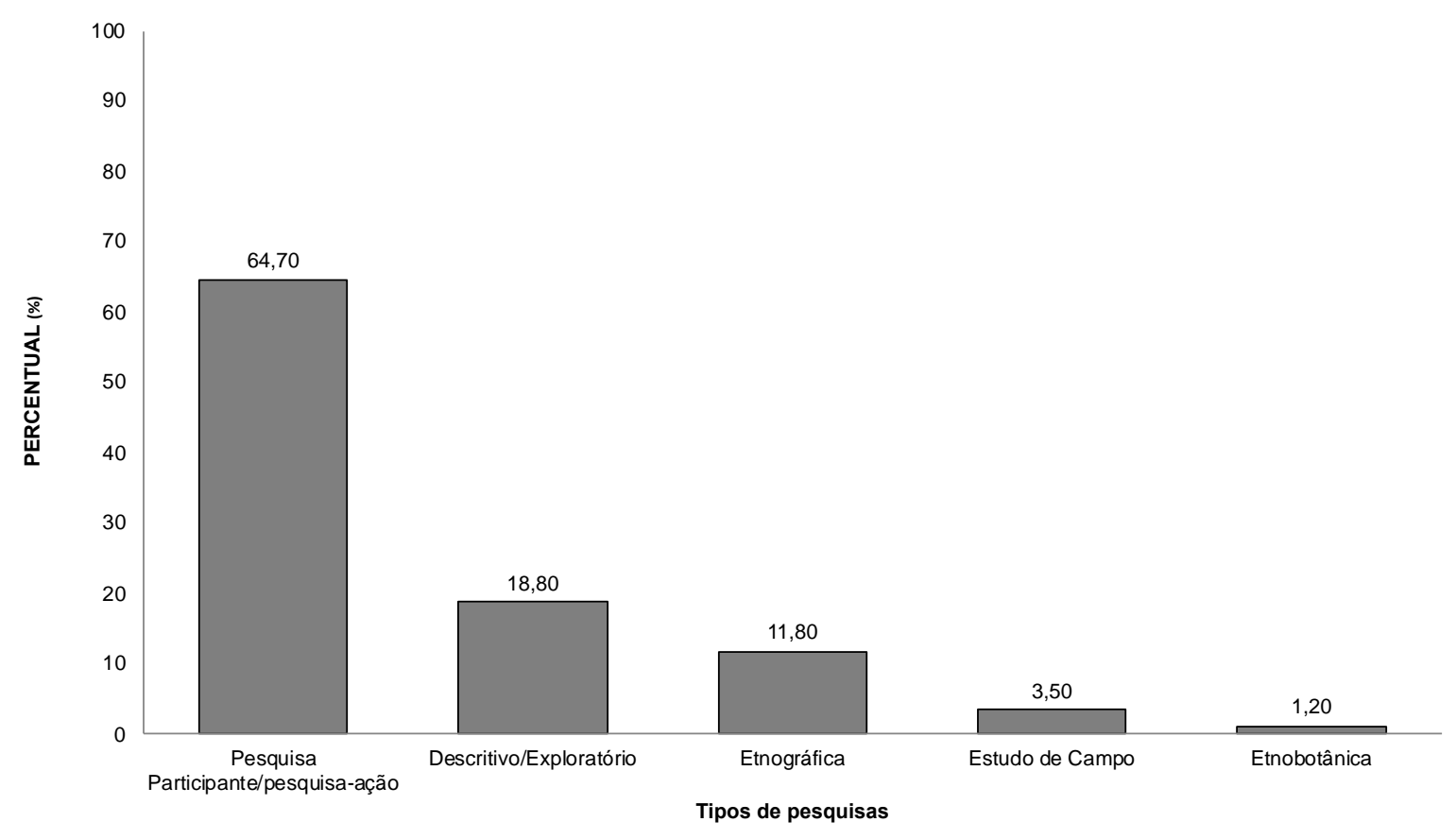

FIGURA 4: Tipos de pesquisas utilizadas em artigos de Educação Ambiental publicados em periódicos nacionais da Área de Educação e Ensino no período de 2005-2018. Fonte: Autores.

A metodologia descritiva/exploratória (18,80\%) (Figura 4) foi utilizada por Souza e Andrade (2014) para analisar a interdisciplinaridade entre saúde e meio ambiente em instituições públicas de ensino superior. Machado e Porto-Martins (2015) realizaram uma pesquisa visando fornecer instrumentos quantitativos para contribuir com o estudo da saúde no trabalho, para tanto combinaram metodologias descritivas, exploratórias e confirmatórias. Costa et al. (2008) realizaram um estudo com a abordagem descritiva nos projetos pedagógicos de duas escolas, uma pública e outra privada, de ensino fundamental na cidade de Rio de Janeiro. Os resultados obtidos pelos autores dizem que os projetos pedagógicos das escolas generalizam as propostas da Educação Ambiental e não especificam a metodologia para se alcançar as ações a serem desenvolvidas.

Dentre os artigos analisados, as autoras Silva et al. (2015) utilizaram a pesquisa etnográfica (11,80\%) (Figura 4) para investigar os modos de vida e as expressões identitárias de uma comunidade no Pantanal do Mato Grosso. Baldin e Munhoz (2011) utilizaram a mesma metodologia durante o desenvolvimento da técnica snowball para trabalhar ações de Educação Ambiental com pescadores da colônia São Pedro, localizada às margens da Lagoa dos Patos, em Pelotas-RS. Steil 
et al. (2010) realizaram uma investigação a partir de uma pesquisa etnográfica em Rincão-Gaia localizado na cidade de Porto Alegre, onde acontecem trilhas educativas, cursos de Educação Ambiental, oficinas ligadas à temática ecológica e atividades de ecoturismo. $\mathrm{O}$ artigo articula suas ideias relacionando ecologia, religião e saúde.

Quanto aos instrumentos de coleta de dados, foram encontrados: análise de conteúdo $(27,66 \%)$, realização de eventos de formação $(12,77 \%)$, aplicação de questionários (12,76\%), condução de entrevistas (10,94\%) e outros (35,87\%) (Figura 5). Em "outros" foram inseridos diversos instrumentos de coleta de dados utilizados pelos autores, a saber: ações de intervenção, análise laboratorial, oficina, açãoreflexão, plataforma, mapa mental, investigação, observação, desenho, osteotécnica, registro fotográfico, registro de vídeo e revisão bibliográfica. Destacase que a análise de conteúdo abordou assuntos relacionados à cidadania, consumo, saúde, mudanças climáticas, aquecimento global, políticas públicas, sustentabilidade, lixo, efeito estufa e resíduos sólidos.

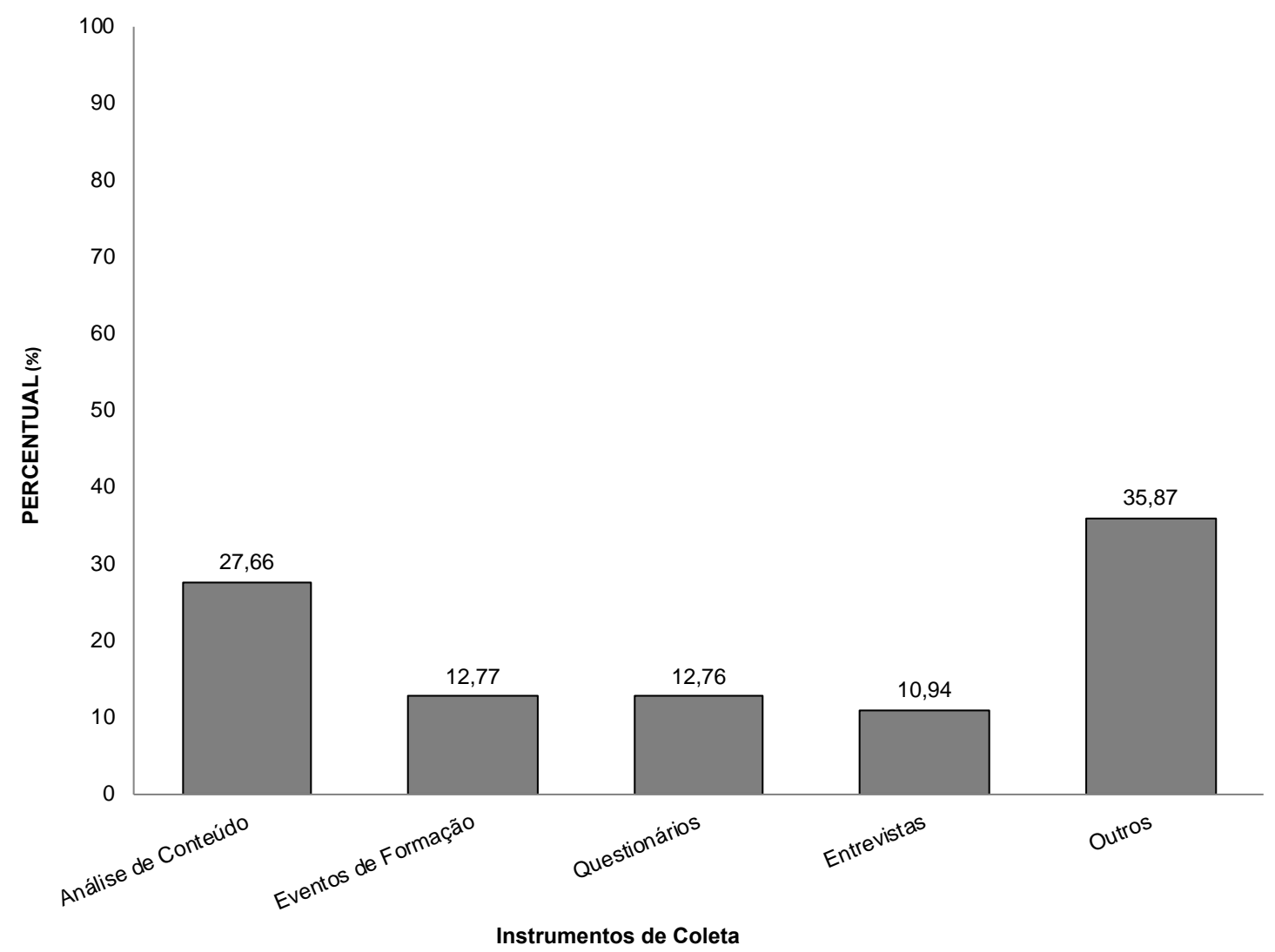

FIGURA 5: Distribuição dos instrumentos de coletas encontrados em artigos de Educação Ambiental publicados em periódicos nacionais da Área de Educação e Ensino no período de 2005-2018. Fonte: Autores.

Do total de artigos selecionados para análise apenas 22 abordaram o tema mudanças climáticas de maneira central (Quadro 1). Para cada artigo foi atribuído um código de identificação composto pela letra $\mathrm{A}$ (artigo) e um número de 1 a 22. Os artigos foram classificados em três grupos (educação, políticas públicas e meio ambiente) distribuídos com base no enfoque principal (Quadro 1). No quadro 1 os artigos estão ordenados em cada grupo a partir do campo "referência". 
QUADRO 1. Relação dos artigos de Educação Ambiental publicados em periódicos nacionais na área de Educação e Ensino no período de 2005-2018 que

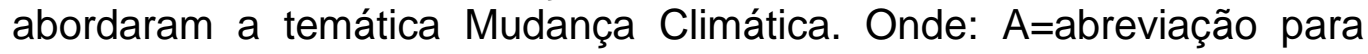
artigo.

\begin{tabular}{|c|c|c|c|}
\hline GRUPO & ARTIGO & TÍTULO & REFERÊNCIA \\
\hline \multirow{4}{*}{ EDUCAÇÃO } & A1 & $\begin{array}{l}\text { Mudanças climáticas, mudanças } \\
\text { globais: desafios para educação. }\end{array}$ & $\begin{array}{l}\text { GUERRA et al. } \\
(2010)\end{array}$ \\
\hline & A18 & $\begin{array}{l}\text { Mudanças Globais: a resposta da } \\
\text { educação. }\end{array}$ & $\begin{array}{l}\text { JACOBI et al. } \\
(2011)\end{array}$ \\
\hline & A20 & $\begin{array}{l}\text { A concepção das ciências e do agir } \\
\text { responsável dos estudantes face às } \\
\text { mudanças climáticas. }\end{array}$ & $\begin{array}{l}\text { BADER et al. } \\
(2014)\end{array}$ \\
\hline & A21 & $\begin{array}{l}\text { Mapeamento de dissertações e } \\
\text { teses brasileiras de educação } \\
\text { ambiental que tratam do tema } \\
\text { mudanças climáticas. }\end{array}$ & $\begin{array}{l}\text { REIS; } \\
\text { (2016) }\end{array}$ \\
\hline \multirow{9}{*}{$\begin{array}{l}\text { POLÍTICAS } \\
\text { PÚBLICAS }\end{array}$} & A3 & $\begin{array}{l}\text { O papel da educação ambiental na } \\
\text { formulação de políticas públicas } \\
\text { transformadoras } \\
\text { enfrentamento das } \begin{array}{r}\text { para } \\
\text { climáticas. }\end{array}\end{array}$ & $\begin{array}{l}\text { VASCONCELOS; } \\
\text { TAMAIO (2010) }\end{array}$ \\
\hline & A19 & $\begin{array}{l}\text { Equidade na adaptação às } \\
\text { mudanças climáticas. }\end{array}$ & MARTINS (2011) \\
\hline & A5 & $\begin{array}{l}\text { Governança de Risco: uma } \\
\text { proposta para lidar com os riscos } \\
\text { ambientais no nível local. }\end{array}$ & $\begin{array}{l}\text { DI GIULIO; } \\
\text { FERREIRA (2013) }\end{array}$ \\
\hline & A6 & $\begin{array}{l}\text { Mercado Global de carbono e } \\
\text { governança global do clima: } \\
\text { desafios e oportunidades. }\end{array}$ & $\begin{array}{l}\text { FARIAS et al. } \\
(2013)\end{array}$ \\
\hline & A15 & $\begin{array}{l}\text { A inclusão da aviação no esquema } \\
\text { Europeu de Comércio de carbono. }\end{array}$ & $\begin{array}{l}\text { GONÇALVES et al. } \\
\text { (2013) }\end{array}$ \\
\hline & A16 & $\begin{array}{l}\text { A construção da estratégia } \\
\text { brasileira de REDD: A simplificação } \\
\text { do debate na priorização da } \\
\text { Amazônia. }\end{array}$ & SOUZA (2013) \\
\hline & A17 & $\begin{array}{l}\text { Inovações para que se democratize } \\
\text { o acesso à energia, sem ampliar as } \\
\text { emissões. }\end{array}$ & $\begin{array}{l}\text { ABRAMOVAY } \\
(2014)\end{array}$ \\
\hline & A11 & $\begin{array}{l}\text { Política de mudança do clima no } \\
\text { município de São Paulo, Brasil: } \\
\text { reflexividade e permeabilidade do } \\
\text { Setor Saúde. }\end{array}$ & $\begin{array}{l}\text { LANDIN; } \\
(2014)\end{array}$ \\
\hline & A8 & $\begin{array}{l}\text { As estratégias de enfrentamento } \\
\text { das mudanças climáticas expressas } \\
\text { nas políticas públicas federais do } \\
\text { Brasil. }\end{array}$ & $\begin{array}{l}\text { NEVES } \\
(2015)\end{array}$ \\
\hline
\end{tabular}




\begin{tabular}{|c|c|c|c|}
\hline & A22 & $\begin{array}{l}\text { Quais seriam as Questões Globais } \\
\text { que definem a Educação } \\
\text { Ambiental? Para além do modismo, } \\
\text { uma análise sistemática e uma } \\
\text { visão sistêmica. }\end{array}$ & SAITO (2017) \\
\hline \multirow{8}{*}{$\begin{array}{l}\text { MEIO } \\
\text { AMBIENTE }\end{array}$} & A12 & $\begin{array}{l}\text { A interface da saúde dos oceanos: } \\
\text { produção de doenças, impactos } \\
\text { socioeconômicos e relações } \\
\text { benéficas. }\end{array}$ & $\begin{array}{l}\text { MOURA et al. } \\
(2011)\end{array}$ \\
\hline & A2 & $\begin{array}{l}\text { Considerações sobre as mudanças } \\
\text { climáticas e os impactos na sub- } \\
\text { bacia do rio Catolé para o município } \\
\text { de Vitória da Conquista-Bahia. }\end{array}$ & $\begin{array}{l}\text { BOMFIM et al. } \\
(2012)\end{array}$. \\
\hline & A4 & $\begin{array}{l}\text { Os desastres ambientais a partir do } \\
\text { olhar midiático. }\end{array}$ & TEIXEIRA (2012) \\
\hline & A7 & $\begin{array}{l}\text { As percepções sobre as variações e } \\
\text { mudanças climáticas e as as aca dos } \\
\text { estratégias de adaptaão dos do Seridó } \\
\text { agricultores familiares do } \\
\text { potiguar. }\end{array}$ & $\begin{array}{l}\text { ANDRADE et al. } \\
(2014)\end{array}$ \\
\hline & A14 & $\begin{array}{lrr}\text { Riscos } & \text { geotécnicos } & \text { e } \\
\text { vulnerabilidade social em } & \text { zonas } \\
\text { costeiras: desigualdade } & \text { e } \\
\text { mudanças climáticas. } & \\
\end{array}$ & $\begin{array}{l}\text { IWAMA et al. } \\
(2014)\end{array}$ \\
\hline & A9 & \begin{tabular}{lrr} 
A remanufatura de & equipamentos \\
eletroeletrônicos & \multicolumn{2}{c}{ como } \\
contribuições & para r \\
desenvolvimento & sustentável: uma \\
avaliação do & caso & dos \\
refrigeradores. & & \\
\end{tabular} & $\begin{array}{l}\text { PAIVA; } \\
\text { (2014) }\end{array}$ \\
\hline & A10 & $\begin{array}{l}\text { Eletricidade para o bombeamento } \\
\text { de água subterrânea: limitações e } \\
\text { oportunidades para respostas } \\
\begin{array}{l}\text { adaptativas às } \\
\text { climáticas. }\end{array}\end{array}$ & SCOTT (2014) \\
\hline & A13 & $\begin{array}{l}\text { Mudanças climáticas e distribuiçãa } \\
\text { social da percepção de risco no } \\
\text { Brasil. }\end{array}$ & $\begin{array}{l}\text { BURSZTYN; EIRÓ } \\
\text { (2015) }\end{array}$ \\
\hline
\end{tabular}

Fonte: Autores.

Nesta parte da pesquisa buscou-se analisar como os artigos de Educação Ambiental relacionam-se com o tema mudanças climáticas. A análise mostrou que esta temática é pouco trabalhada nas publicações. Quatro artigos relacionaram mudanças climáticas e educação (A1, A18, A20 e A21) (Quadro 01). Nestes artigos os autores fazem uma reflexão sobre os desafios que os professores enfrentam para lecionar o tema. São comentadas práticas educativas desenvolvidas em outros países e pontos importantes da educação ambiental no Brasil. Os autores propõem uma educação ambiental que transversalize as questões das mudanças climáticas 
no currículo, nos processos de formação inicial e continuada de professores, e nas práticas conduzidas em sala de aula.

É importante destacar o trabalho A21 onde os autores analisaram 17 dissertações publicadas no banco de teses da CAPES entre 1987 e 2010. Os resultados das análises mostraram picos de produção entre 2008 e 2010 (12 dissertações no período) abordando principalmente o contexto escolar (ensino médio), produção concentrada nas regiões Sul e Sudeste, e número reduzido de trabalhos que versam sobre a temática Mudanças Climáticas. Tais dados corroboram que a delimitação inicial do recorte temporal proposto neste trabalho é válida.

Dez artigos versam sobre mudanças climáticas e políticas públicas (Quadro 1). Em A3 os autores propõem pensar uma política pública de Educação Ambiental para o enfrentamento das mudanças climáticas, bem como a construção de alternativas viáveis para a redução da emissão de GEE e a construção de uma sociedade de baixo carbono. Nesta proposta o educador ambiental tem grande importância na formação do aluno. A15 traz uma reflexão sobre o avanço da ciência e a contundência dos dados divulgados nos últimos anos pelo IPCC. O trabalho afirma que mesmo nos cenários mais otimistas de mitigação, ou seja, de maior redução das emissões de GEE, ainda serão necessárias adaptações para garantir a segurança da sociedade, principalmente em países mais vulneráveis.

No A5 os autores questionam a complexidade e as incertezas científicas relacionadas às mudanças ambientais e climáticas, bem como riscos associados em nível local. Neste trabalho é defendido um novo modelo de produção de conhecimento e de tomada de decisão, identificada como governança de risco, útil em nível local. Nos artigos A6, A16, A17 e A19 os autores destacam que as mudanças climáticas representam um desafio aos governos, mercado e sociedade civil no sentido de forçar a busca por novas alternativas possíveis a mitigação e/ou adaptação. Até o momento o foco tem sido o mercado global de carbono. Mesmo com os avanços no número de projetos de redução de GEE após o protocolo de Kyoto, principalmente em países em desenvolvimento, ainda se faz necessário promover ações que possam alcançar a eficácia que o problema das mudanças climáticas requer.

Em A11 os autores analisaram como o setor da saúde se articula com a implantação de uma política municipal de mudança do clima. Segundo estes é necessário considerar a dialética global-local, pois em termos de saúde ambiental o agir local e o pensar global impulsionam o modelo para nexos e mudanças estruturais, pois certas condicionantes de causalidade do risco e de vulnerabilidades estão além das escalas demarcadas.

No artigo A8 os autores analisaram a estratégia de enfrentamento das mudanças climáticas no Brasil expressas na Política Nacional sobre Mudança do Clima (PNMC). De acordo com os autores esta política privilegia ações de mitigação em detrimento daquelas voltadas à adaptação.

Em A22 o autor analisa Questões Globais que desafiam a Educação Ambiental, para além do modismo. Segundo o autor, apesar de haver uma visão que sempre remete mudanças climáticas às questões globais em Educação Ambiental os documentos da Organização das Nações Unidas (ONU) com foco nas Décadas e Anos Internacionais como pautas prioritárias para o globo não destacam a temática mudanças climáticas. Por outro lado, o tema Água foi mais recorrente. Contudo, não se pode concluir que o tema mudanças climáticas seja ignorado, pois o Painel Intergovernamental sobre Mudanças Climáticas (IPCC) está no abrigo da ONU. 
Relacionando mudanças climáticas e meio ambiente foram encontrados oito artigos (Quadro 1). De modo geral os autores comentam sobre a vulnerabilidade do homem às mudanças climáticas, além dos efeitos da pressão antrópica sobre a natureza e, consequente, esgotamento dos recursos naturais.

No que se refere aos fundamentos teóricos, nenhum dos trabalhos discutiu o uso da concepção de práxis educacional sustentada na visão de Paulo Freire. Quanto às correntes de Educação Ambiental, percebe-se predomínio das vertentes conservadora e pragmática, contudo é notável no conjunto dos trabalhos analisados o aparecimento de elementos da visão crítica.

\section{CONCLUSÃO}

Os dados analisados mostraram que os artigos de Educação Ambiental publicados em periódicos nacionais trabalham principalmente as relações entre homem, natureza, sociedade e sustentabilidade, aqui tratados como Educação Ambiental lato sensu, pois estes aspectos envolvem as diferentes vertentes da Educação Ambiental. As perspectivas teóricas dos artigos estão voltadas sobretudo para a sustentabilidade, percepção dos problemas ambientais em diferentes escalas e para as políticas públicas nas esferas federal, estadual e municipal. Este contexto corrobora o fato da maioria dos artigos ter por objetivos o desenvolvimento de ações de Educação Ambiental e o diagnóstico de determinada problemática. Assim, as pesquisas são do tipo participante/pesquisa-ação ou ainda pesquisa descritiva/exploratória, em sua maioria. Por fim, os instrumentos de coleta de dados foram majoritariamente voltados à análise de conteúdo, eventos de formação, aplicação de questionários e realização de entrevistas.

Destacamos que o método de análise empregado foi conveniente, pois as categorias corroboram-se entre si e mostram um retrato autêntico dos artigos publicados em periódicos nacionais que envolvem a Educação Ambiental.

Constatamos que a temática mudanças climáticas é pouco trabalhada no contexto da Educação Ambiental nacional, sendo uma importante lacuna a ser observada pelos estudiosos da área.

\section{AGRADECIMENTOS}

A primeira autora agradece à UEG e à FAPEG pela concessão de bolsas de estudos durante o mestrado.

\section{REFERÊNCIAS}

ABREU, C. R. O campo de pesquisa da Educação Ambiental e suas relações com o tema mudanças climáticas. Dissertação de Mestrado em Ensino de Ciências, Universidade Estadual de Goiás, Anápolis, Goiás. 71p. 2017.

ABRAMOVAY, R. Inovações para que se democratize o acesso à energia, sem ampliar as emissões. Ambiente \& Sociedade, v. XVII, n. 3, p. 1-18, 2014.

ANDRADE, A. J. P.; SILVA, N. M.; SOUZA, C. R. As percepções sobre as variações e mudanças climáticas e as estratégias de adaptação dos agricultores familiares do Seridó potiguar. Desenvolvimento e Meio Ambiente, v. 31, p. 77-96, 2014. DOI: $10.5380 \% 2 F d m a . v 31$ i0.32955 
BADER, B.; JEZIORSKI, A.; THERRIAULT, G. A concepção das ciências e do agir responsável dos estudantes face às mudanças climáticas. Educação em Foco, n. 23, p. 153-179, 2014. DOI: http://dx.doi.org/10.24934/eef.v17i23.538

BALDIN, N.; MUNHOZ, E. M. B. Educação ambiental comunitária: uma experiência com a técnica de pesquisa snowball (bola de neve). Revista Eletrônica do Mestrado em Educação Ambiental, v. 27, p. 46-60, 2011. DOI: https://doi.org/10.14295/remea.v27i0.3193

BARROS, V.; TOZONI-REIS, M. Reinventando o ambiente: Educação Ambiental na Educação Infantil. Cadernos de Educação, n. 34, p. 135-151, 2009.

BOMFIM, A. M.; ANJOS, M. B.; FLORIANO, M. D.; FIGUEIREDO, C. S. M.; SANTOS, D. A.; SILVA, C. L. C. Parâmetros curriculares nacionais: uma revisita aos temas transversais meio ambiente e saúde Trabalho, Educação e Saúde, v. 11, n. 1, p. 27-52, 2013.

BRASIL. Lei no 9.795, de 27 de abril de 1999. Dispõe sobre a educação ambiental, institui a Política Nacional de Educação Ambiental e dá outras providências. Diário Oficial da União, Brasília, DF, 28 abr. 1999. Disponível em: <http://www.planalto.gov.br/ccivil_03/leis/19795.htm>

BRASIL. Ministério do Meio Ambiente. Lei no 12.187, de 29 de dezembro de 2009. Dispõe sobre a educação ambiental, Institui a Política Nacional sobre Mudança do Clima - PNMC em: <http://www.planalto.gov.br/ccivil_03/_ato20072010/2009/lei/l12187.htm>

BRASIL. Programa Nacional de Educação Ambiental - ProNEA. Ministério do Meio Ambiente, Diretoria de Educação Ambiental; Ministério da Educação. Coordenação Geral de Educação Ambiental. - 3. ed - Brasília: Ministério do Meio Ambiente, 2005. 102p.

BURSZTYN, M.; EIRÓ, F. Mudanças climáticas e distribuição social da percepção de risco no Brasil. Mudanças climáticas e distribuição social da percepção de risco no Brasil. Revista Sociedade e Estado, v. 30, n. 2, 2015.

CORREIA, M. M. Concepções de futuras professoras do ensino básico acerca do ambiente, da educação ambiental e das estratégias didáticas em educação ambiental. Ensaio, v. 16, n. 01, p. 15-29, 2014. DOI: http://dx.doi.org/10.1590/198321172014160102.

COSTA, M. F. B.; MONTEIRO, S. C. F.; COSTA, M. A. F. Projeto de educação ambiental no ensino fundamental: bases para práticas pedagógicas. Revista Eletrônica Mestrado Educação Ambiental, v. 21, p. 133-144, 2008.

DANTAS, V. R.; ABÍLIO, F. J. P. A Educação Ambiental no Âmbito Escolar: Análise de conteúdo de artigos publicados na Revista Eletrônica do Mestrado em Educação Ambiental - REMEA (período 2004-2013). Revista eletrônica do Mestrado em Educação Ambiental, v. 31, n. 2, p.177-197, 2014. 
DELIZOICOV, D.; LORENZETTI, L. Alfabetização Científica no contexto das séries iniciais. Ensaio Pesquisa em Educação em Ciências, América do Norte, 325 11, 2008.

DI GIULIO, G. M.; FERREIRA, L. C. Governança do risco: uma proposta para lidar com riscos ambientais no nível local. Desenvolvimento e Meio Ambiente, v. 28, p. 29-39, 2013.

FARIAS, C. R. O.; CARVALHO, W. L. P. Desvelando relações ciência-tecnologiasociedade-ambiente a partir de um processo judicial sobre danos ambientais. Revista eletrônica Mestrado Educação Ambiental, v. 17, p. 316-330, 2006.

FARIAS, L. G. Q.; VENTURA, A. C.; PAIVA, D. S.; GOMES, G. A. M. M.; ANDRADE, J. C. S. Mercado global de carbono e governança global do clima: desafios e oportunidades. Desenvolvimento e Meio Ambiente, v. 28, p. 11-27, 2013. DOI: http://dx.doi.org/10.5380/dma.v28i0.29927

FERNANDES, G. W.; COELHO, M. S.; MACHADO, R. B.; FERREIRA, M. E.; AGUIAR, L. M. S.; DIRZO, R.; SCARIOT, A.; LOPES, C. R. Afforestation of savanas: an impeding ecologial disaster. Natureza \& Conservação, v. 14, p. 24-27, 2016.

FERREIRA, M. E.; ANJOS, A. F.; FERREIRA, L. G.; BUSTAMANTE, M.; FERNANDES, G. W.; MACHADO, R. B. Cerrado: o fim da história ou uma nova história? Ciência Hoje, v. 56, n. 334, p. 24-29, 2016.

GOMES, V. S.; DIAS, C. M. S.; GALIAZZI, M. C. Saberes e fazeres identitários: a narrativa produzindo professores educadores ambientais. Educação. v. 32, n. 3, p. 301-310, 2009.

GONÇALVES, P. W.; LAGUNA SICCA, N. A.; DE SOUSA FERNANDES, S. A.; SILVEIRA GALAN FERNANDES, M. C. Inovações didáticas e a concepção de natureza: a pesquisa colaborativa e o desenvolvimento profissional do professor. Educação Unisinos, v. 17, n. 3, p. 250-260, 2013.

GUERRA, A. F. S; JACOBI, P.; SULAIMAN , S. N.; NEPOMUCENO, T. Mudanças climáticas, mudanças globais: desafios para a educação. Rio Grande do Sul. Revista eletrônica do Mestrado em Educação Ambiental, v. especial, p. 88-105, 2010.

IPCC, 2001. Climate Change 2001: The Scientific Basis. Contribution of Working Group I to the Third Assessment Report of the Intergovernmental Panel on Climate Change. HOUGHTON, J. T.; DING, Y.; GRIGGS, D. J.; NOGUER, M.; van der LINDEN, P. J.; DAI, X.; MASKELL, K.; JOHNSON, C. A. (Eds.). Cambridge University Press, Cambridge, United Kingdom and New York, NY, USA, 881p.

IPCC, 2014: Climate Change 2014: Synthesis Report. Contribution of Working Groups I, II and III to the Fifth Assessment Report of the Intergovernmental Panel on Climate Change [Core Writing Team, R.K. Pachauri and L.A. Meyer (eds.)]. IPCC, Geneva, Switzerland, $151 \mathrm{p}$. 
IWAMA, A. Y.; BATISTELLA, M.; FERREIRA, L. C. Riscos geotécnicos e vulnerabilidade social em zonas costeiras: desigualdades e mudanças climáticas. Ambiente \& Sociedade, v. XVII, n. 4, p. 251-274, 2014.

JACOBI, Pedro Roberto et al. Mudanças climáticas globais: a resposta da educação. Revista brasileira de educação, v. 16, n. 46, p. 135-148, 2011.

JIMENEZ, S.; TERCEIRO, E.. A crise ambiental e o papel da educação: um estudo fundado na ontologia marxiana. Educação em Revista, v. 25, n. 3, p. 299-325, 2009.

LANDIN, R.; GIATTI, L. L. Política de mudança do clima no município de São Paulo, Brasil: reflexividade e permeabilidade do Setor Saúde. Ciência \& Saúde Coletiva, v. 19, n. 10, p. 4149-4156, 2014.

LATINI, R. M.; SOUSA, A. C. Ensino de Química e Ambiente: as articulações presentes na revista Química Nova na Escola (QNEsc). Investigações em Ensino de Ciências, v. 16, n. 1, p. 143-159, 2011.

LAYRARGUES, P. P. Para onde vai a educação ambiental? O cenário políticoideológico da educação ambiental brasileira e os desafios de uma agenda política crítica contra-hegemônica. Revista Contemporânea de Educação, v. 7, n. 14, p. 388-411, 2012. DOI: https://doi.org/10.20500/rce.v7i14.1677

LAYRARGUES, P. P.; LIMA, G. F. C. As macrotendências político-pedagógicas da educação ambiental brasileira. Ambiente \& Sociedade, v. XVII, n. 1, p. 23-40, 2014.

LIMA, L. C. Modelo aberto de educação ambiental. Educação, Temática e Digital, v. 15, n. 1, p.161-178, 2013.

MACÊDO, M. P. W.; SOUZA, M. F. Percepção de professores da rede pública sobre problemas ambientais no Rio Grande do Norte, Brasil. Revista Eletrônica do Mestrado em Educação Ambiental. Ed. Especial Impressa - Dossiê Educação Ambiental, p. 119-131, 2014. DOI: https://doi.org/10.14295/remea.v31i2.3464

MACHADO, P. G. B.; PORTO-MARTINS, P. C. Proposta de protocolo: indicadores de saúde-enfermidade laboral. Trabalho \& Educação, v. 24, n. 2, p. 281-293, 2015.

MAIO, V.; CAMPOS, F.; MONTEIRO, M. E.; HORTA, M. J. Com os outros aprendemos, descobrimos e construímos um projecto colaborativo na plataforma Moodle. Educação, Formação \& Tecnologias, v.1, p. 21-31, 2008. disponível no URL: http://eft.educom.pt.

MALAFAIA, G.; RODRIGUES, A. S. L. Uma reflexão sobre o ensino de Ciências no nível fundamental da educação. Ciência \& Ensino, vol. 2, n. 2, 2008.

MAGALHÃES, C. J. A. O.; TOMANIK, E. A. Representações sociais e direcionamento para a educação ambiental na reserva biológica das perobas. Paraná. Investigações em Ensino de Ciências, v. 17, n. 1, p. 227-248, 2012. 
MARTINS, R. D'A. Equidade na adaptação às mudanças climáticas. Política \& Sociedade, v. $10, \quad n$ 19, p. 335-344, 2011 . DOI: 10.5007/21757984.2011v10n19p335

MIRANDA, S. C. Variação espacial e temporal da biomassa vegetal em áreas de Cerrado. Tese de Doutorado, Universidade de Brasília, Departamento de Ecologia. 2012. $141 \mathrm{p}$.

MIRANDA, S.C.; ABREU, C.R.; DE-CARVALH, P.S. As mudanças climáticas no contexto da Educação Ambiental. In: PORTO, M.D.; SANTOS, M.L.; FERREIRA, J.R. Os desafios do Ensino de Ciências no século XXI e a formação de professores para a Educação Básica. Curitiba-PR: CRV, 2016.

MOURA, J. F.; CARDOZO, M.; BELO, M. S. S. P.; HACON, S.; SICILIANO, S. A interface da saúde pública com a saúde dos oceanos: produção de doenças, impactos socioeconômicos e relações benéficas. Ciência \& Saúde Coletiva, v. 16, n. 8, p. 3469-3480, 2011.

NEVES F. M.; CHANG, M.; PIERRI, N. As estratégias de enfrentamento das mudanças climáticas expressas nas políticas públicas federais do Brasil. Desenvolvimento e Meio Ambiente, v. 34, p. 5-23, $2015 . \quad$ DOI: http://dx.doi.org/10.5380/dma.v34i0.37739

OLIVEIRA, R. F.; ALVES, J. W. S. Mudanças climáticas globais no estado de São Paulo. Secretaria do Meio Ambiente/CETESB. São Paulo: SMA, (Cadernos de Educação Ambiental), 88p., 2011.

OLIVEIRA, M. G.; CARVALHO, L. M. Políticas Públicas de formação de professores e de Educação Ambiental: possíveis articulações? Revista Contemporânea de Educação, v. 7, n. 14, 2012.

PBMC. Base científica das mudanças climáticas. Contribuição do Grupo de Trabalho 1 do Painel Brasileiro de Mudanças Climáticas ao Primeiro Relatório da Avaliação Nacional sobre Mudanças Climáticas. AMBRIZZI, T., ARAÚJO, M. (Eds.). COPPE. Universidade Federal do Rio de Janeiro, Rio de Janeiro, RJ, Brasil. 2014.

PAIVA, L. M.; SERRA, E. G. A remanufatura de equipamentos eletroeletrônicos como contribuição para o desenvolvimento sustentável: Uma avaliação do caso dos refrigeradores. Desenvolvimento e Meio Ambiente, v. 29, p. 185-200, 2014.

PALÁCIOS, C. M.; DAL'FARRA, R. A.; GELLER, M. Concepções sistêmicas na educação ambiental: uma experiência com alunos do ensino fundamental. Revista Brasileira de Pesquisa em Educação em Ciências, v. 11, n. 1, 2011.

PATO, C.; SA, L. M.; CATALAO, V. L. Mapeamento de tendências na produção acadêmica sobre Educação Ambiental. Educação em Revista, v. 25, n. 3, p. 213233, 2009. DOI: http://dx.doi.org/10.1590/S0102-46982009000300011. 
PITANO, S. C.; NOAL, R. E. Horizontes de diálogo em educação ambiental: contribuições de Milton Santos, Jean-Jacques Rousseau e Paulo Freire. Educação em Revista, v. 25, n. 3, p. 283-298, 2009.

REIS, D. A.; SILVA, L. F. Mapeamento de dissertações e teses brasileiras de educação ambiental que tratam do tema mudanças climáticas. Revista Eletrônica do Mestrado em Educação Ambiental, v. 33, n. 1, 2016. DOI: https://doi.org/10.14295/remea.v33i1.4642

RINK, J.; MEGID NETO, J. Tendências dos artigos apresentados nos encontros de pesquisa em educação ambiental (EPEA). Educação em Revista, v. 25, n. 3, p. 235-263, 2009.

RODRIGUES, L. L.; FARRAPEIRA, C. M. R. Percepção e educação ambiental sobre o ecossistema manguezal incrementando as disciplinas de ciências e biologia em escola pública do Recife-PE. Recife. Investigações em Ensino de Ciências, v. 13, n. 1, p. 79-93, 2008.

SAITO, C. H. As mútuas interfaces entre projetos e ações de educação ambiental e de gestão de recursos hídricos: subsídios para políticas de estado Campinas. Ambiente \& Sociedade, v. 14, n. 1, p. 213-227, 2011. DOI: http://dx.doi.org/10.1590/S1414-753X2011000100012

SAITO, C. H. Quais seriam as questões globais que desafiam a educação ambiental? Para além do modismo, uma análise sistemática e uma visão sistêmica. Revista Eletrônica do Mestrado em Educação Ambiental, Edição Especial XVI Encontro Paranaense de Educação Ambiental, p. 4-24, 2017. DOI: https://doi.org/10.14295/remea.v0i0.7138

SAUVÉ, L. Uma cartografia das correntes em educação ambiental. Educação Ambiental: Pesquisa e Desafio, p. 17-44, 2005.

SAMPAIO, S. M. C.; GUIMARÃES, L. B. Educação ambiental: tecendo trilhas, escriturando territórios. Educação em Revista, v. 25, n. 03, p. 353-368, 2009. DOI: http://dx.doi.org/10.1590/S0102-46982009000300017.

SANTOS, N. L.; SILVA, M. M. P. Por que educação ambiental não tem alcançado mudanças significativas na sociedade contemporânea? Uma análise de artigos publicados em eventos científicos no Brasil de 2005 a 2010. Revista eletrônica do Mestrado em Educação Ambiental, v. 27, p. 122-138, 2011. DOI: https://doi.org/10.14295/remea.v27i0.3198

SCOTT, C. A. Eletricidade para o bombeamento de água subterrânea: limitações e oportunidades para respostas adaptativas às mudanças climáticas. Desenvolvimento e Meio Ambiente, v. 30, p. 45-57, $2014 . \quad$ DOI: http://dx.doi.org/10.5380/dma.v30i0.35588

SILVA, R. B. L.; SILVA, R. S. P.; CANTUÁRIA, P. C.; FREITAS, J. L.; SOUTO, R. N. P.; CANTUÁRIA, M. F. Projetos de educação ambiental nas redes de ensino 
estadual e municipal na cidade de Macapá, Amapá, Brasil. Biota Amazônica, v. 5, n. 4, p. 102-109, 2015. Disponível em: http://periodicos.unifap.br/index.php/biota

SILVA, A. S. A prática pedagógica da Educação Ambiental. Um estudo de caso sobre o colégio militar de Brasília. 123 p. Tese (Mestrado em Centro de Desenvolvimento Sustentável). Brasília, 2008.

SOUZA, C. A. A construção da estratégia brasileira de REDD: a Simplificação do debate na priorização da Amazônia. Ambiente \& Sociedade, v. XVI, n. 1, p. 99-116, 2013.

SOUZA, C. L.; ANDRADE, C. S. Saúde, meio ambiente e território: uma discussão necessária na formação em saúde. Ciência \& saúde coletiva, v. 19, n. 10, p.41134122. 2014. DOI: http://dx.doi.org/10.1590/1413-812320141910.08992014.

STEIL, C. A.; CARVALHO, I. C. M.; PASTORI, E. O. Educação Ambiental no Rincão Gaia: pelas trilhas da saúde e da religiosidade numa paisagem ecológica. Educação, v. 33, n. 1, p. 54-64, 2010.

TEIXEIRA, D. V. Os desastres ambientais a partir do olhar midiático. Revista eletrônica Mestrado Educação Ambiental, v. 28, p. 419-433, 2012.

VALVERDE, M. C.; MARENGO, J. A. Mudanças na circulação atmosférica sobre a América do Sul para cenários futuros de clima projetados pelos modelos globais do IPCC AR4. Revista Brasileira de Meteorologia, v. 25, n. 1, p. 125 - 145, 2010.

VALENTI, M. W.; OLIVEIRA, H. T.; DODONOV, P.; SILVA, M. M. Educação ambiental em unidades de conservação: políticas públicas e a prática educativa. Educação em Revista, v. 28, n. 1, p. 267-288, 2012. DOI: http://dx.doi.org/10.1590/S0102-46982012000100012

VASCONCELOS, C. R.; TAMAIO, I. O papel da educação ambiental na formulação de políticas públicas transformadoras para enfrentamento das mudanças climáticas. Revista eletrônica do Mestrado em Educação Ambiental, v. especial, p. 79-87, 2010.

VIEIRA, K. R. C. F.; BAZZO, W. A. Discussões acerca do aquecimento global: uma proposta CTS para abordar esse tema controverso em sala de aula. Ciência \& Ensino, v. 1, número especial, p. 2007. 